\title{
Rüzgar Enerjisi ve Çevresel Potansiyelinin Keşan Örneği Üzerinden İncelenmesi
}

\author{
Analysis of Wind Energy and Environmental Potential: Keşan Case

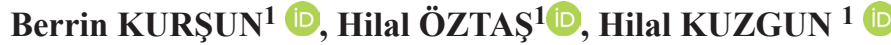 \\ ${ }^{1}$ Marmara Üniversitesi Mühendislik Fakültesi., Kimya Mühendisliği Bölümü
}

Öz

Enerji ihtiyacının sürekli artması, yaygın kullanılan enerji kaynaklarının kısıtlı, tükenebilir ve çevreye zararlı olması alternatif enerji kaynaklarının kullanılmasını gerekli kılmıştır. Bu çalışmada amaç, rüzgar enerjisinin mesken elektrik enerjisi ihtiyacını karşılamakta ne kadar sürdürülebilir bir seçenek olduğunu incelemektir. İnceleme sonucunda, Edirne ili rüzgar türübini kurulumu için en uygun bölgelerden biri olarak belirlenmiştir. Edirne'de ekonomik olarak rüzgar enerji santrali (RES) kurulumu için uygun rüzgar hızı ve kapasite faktörü değerine sahip bölgelerinden olan Keşan ilçesi için 2018 yılı nüfusu ve nüfusun gerekli mesken elektrik ihtiyacı dikkate alındığında, 19 MW' lık bir RES yatırımının ilçenin mesken elektrik ihtiyacını karşılayacağı tespit edilmiştir. Yapılan projeksiyon çalışmaları sonucunda 2050 yılına kadar gerekli mesken elektrik ihtiyacının karşılanması için ise 165 MW'lık RES kurulması gerekmektedir. Ayrıca, çalışmamızda rüzgar enerjisinden elektrik eldesi sonucunda oluşan $\mathrm{CO}_{2}$ salınımları ile Türkiye'de mevcut durumda elektrik üretimi sonucu $\mathrm{CO}_{2}$ salınımları karşılaştırılmıştır. Elektrik ihtiyacının rüzgar enerjisiyle karşılanması durumunda, $\mathrm{CO}_{2}$ salınımında $\mathbf{0 9 7 , 9 6}$ azalma sağlanacağı belirlenmiştir. Keşan özelinde rüzgar enerjisinin 2050 yılına kadar Keşan'daki elektrik ihtiyacını karşılama potansiyeline sahip olduğu belirlenmiş ve Türkiye'nin rüzgar enerji potansiyelini maksimum kapasitede kullanması ile ülkenin karbon salınımı azaltım hedeflerine ulaşılmasında büyük katk1 sağlayabilecek düzeyde olduğu belirlenmiştir.

Anahtar Kelimeler: yenilenebilir enerji, rüzgar enerjisi ile elektrik üretimi, rüzgar türbinleri

\begin{abstract}
Increasing energy demand, limitedness of fossil fuels and adverse effects of fossil fuels necessitates the utilization of alternative energy technologies. Here the aim is to assess the sustainability of wind power to meet the domestic electricity demand. In this study, areas feasible to implement wind turbines in Turkey are evaluated according to their wind energy potential. Edirne is found to be one of the most feasible areas to implement wind turbines strategically. When the population in Keşan (one of the most feasible areas in terms of wind speed and capacity factor in Edirne) and necessary electricity quantity are considered for the base year 2018, it is found that wind turbine with a total capacity of $19 \mathrm{MW}$ can meet this demand. When projection till 2050 is performed, $165 \mathrm{MW}$ capacity can meet necessary demand quantity. Additionally, $\mathrm{CO}_{2}$ emissions via electricity generation with wind and current energy mix in Turkey have been compared. \%97,96 $\mathrm{CO}_{2}$ emission reduction is found with wind electricity generation. Also, there is enough wind energy potential in Keşan to meet energy de-

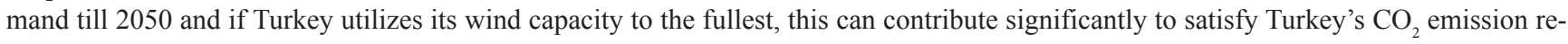
duction targets.
\end{abstract}

Keywords: renewable energy, electricity generation via wind energy, wind turbines

\section{I.GİRIŞ}

Enerji kalkınmanın ayrılmaz bir parçasıdır. Günümüzde enerji ihtiyacının karşılanmasında büyük oranda fosil yakıtlardan (\%78) yararlanılmaktadır. Fosil kaynakların kullanımına bağlı sera gazı salınımları (\%40 enerji üretimi kaynaklı), küresel ısınmanın başlıca nedenlerinden biridir [1]. Ayrıca, fosil yakıtların sebep olduğu hava kirliliği, asit yağmurları gibi çevresel problemlerin yanı sıra fosil yakıtların tükenir oluşu, fiyatlarındaki dalgalanmalar da alternatif yenilenebilir enerji kaynaklarının 
kullanılmasını zorunlu hale getirmektedir [1,2]. Türkiye elektrik üretimde büyük oranda ithal ettiği doğalgaz ve kömürü kullanmaktadır. Bu da, ülkemizin enerji enerji güvenliği ve bağımsızlığı açısından olumsuzluklar yaratmaktadır. $\mathrm{Bu}$ sebeplerle, Türkiye enerji güvenliği açısından ve enerji üretimine bağll çevresel problemlerini çözmek için yerel yenilenebilir enerji kaynaklarından daha büyük oranlarda yararlanmalıdır. Bu bağlamda, yüksek potansiyeli ile rüzgar enerjisi Türkiye için en önemli yenilenebilir enerji kaynaklarından biridir [3, 4].

Yeryüzüne ulaşan güneş enerjisinin \%1-2'lik kısmı rüzgar enerjisine dönüşmektedir. Farklı ısınan hava kütlelerinin düşük ve yüksek basınç bölgeleri oluşturması sonucunda, yüksek basınç bölgesinden düşük basınç bölgesine hava akımı rüzgarları oluşturur. Basınç merkezleri arasındaki basınç farkı ne kadar yüksekse rüzgar gücü o denli şiddetli olmaktadır [5]. Rüzgarın içerdiği kinetik enerji, rüzgar türbinleri ile önce mekanik enerjiye daha sonra elektrik enerjisine dönüştürülür. Gelişim aşamaları içinde pek çok rüzgar türbin tipi olmasına karşın günümüzde elektrik üretimi için genellikle üç kanatlı, yatay eksenli, rüzgarı karşıdan alan (upwind) rüzgar türbinleri yüksek verim özellikleri nedeniyle tercih edilmektedir [6,7]

Dünya Bankası ve Danimarka Teknik Üniversitesi işbirliği ile oluşturulan küresel rüzgar potansiyeli atlası şekil 1 'de görülmektedir. Buna göre, Dünya'da okyanus/deniz k1yıs1 ve yüksek bölgeler daha yüksek rüzgar enerjisi potansiyeline sahiptir [8]. Kurulu rüzgar gücü kapasitesi açısından Çin, Amerika Birleşik Devletleri, Almanya ve Hindistan öncü devletlerdir ve kurulu rüzgar gücü kapasitesinin $\% 73$ ’ü bu devletlerde bulunmaktadır [1].

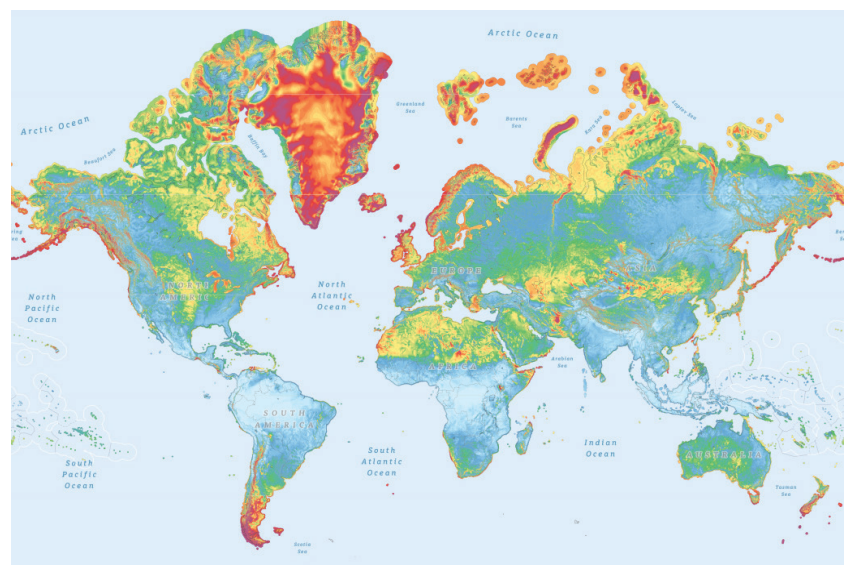

Şekil 1: Küresel rüzgar enerjisi potansiyeli atlası [8].

Rüzgâr enerji santrallerinin, ekonomik yatırımlar olabilmesi için $50 \mathrm{~m}$ 'de $7 \mathrm{~m} / \mathrm{s}$ üzeri rüzgar hızı, 0,35 ve üzeri kapasite faktörü (rüzgardaki kinetik enerjinin ne oranda elektrik enerjisine çevrilebileceğini gösteren parametre) gereklidir. Bu bağlamda değerlendirildiğinde Türkiye'de rüzgâr enerji potansiyelinin en iyi olduğu alanların kıyı şeritleri, yüksek bayırlar ve dağların tepe noktaları olduğu gözlemlenmiştir. Yenilenebilir Enerji Genel Müdürlüğü (YEGM) tarafından Türkiye'de $50 \mathrm{~m}$ yükseklikte ölçülen rüzgâr hızlarına göre illerin rüzgâr potansiyelleri belirlenmiştir. Rüzgâr potansiyeli yüksek olan iller; Balıkesir, Çanakkale, İzmir, Manisa, Samsun, Muğla ve Tekirdağ olarak tespit edilirken, ayrıca İstanbul, Bursa, Mersin, Edirne, Hatay, Kırklareli, Tokat, Aydın gibi illerin de oldukça iyi rüzgâr potansiyeline sahip olduğu bulunmuştur [9].

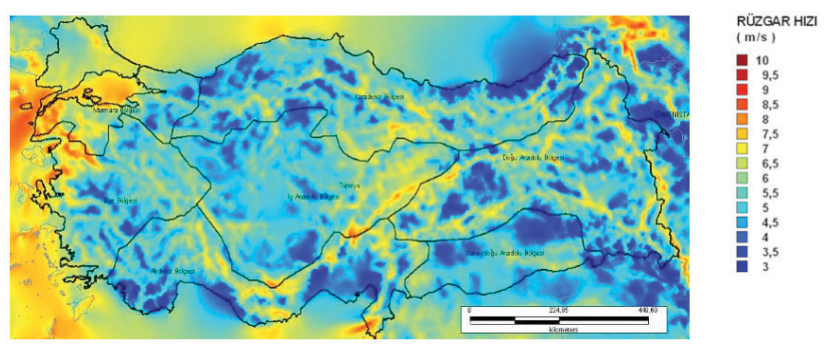

Şekil 2: Türkiye'de rüzgar potansiyeli atlası [9].

Türkiye'de kurulu rüzgar gücü incelendiğinde hılı bir artış gözlenmektedir. 2018 yılı temmuz ayı itibariyle kurulu güç $7000 \mathrm{MW}$ 'a yaklaşmış ve toplam elektrik tüketiminin yaklaşık \%6,0'lık kısmını karşılar duruma gelmiştir. Bu haliyle rüzgar enerjisi Türkiye'de kurulu kapasitesi en hızlı artan yenilenebilir enerji kaynağı olmuştur [10].

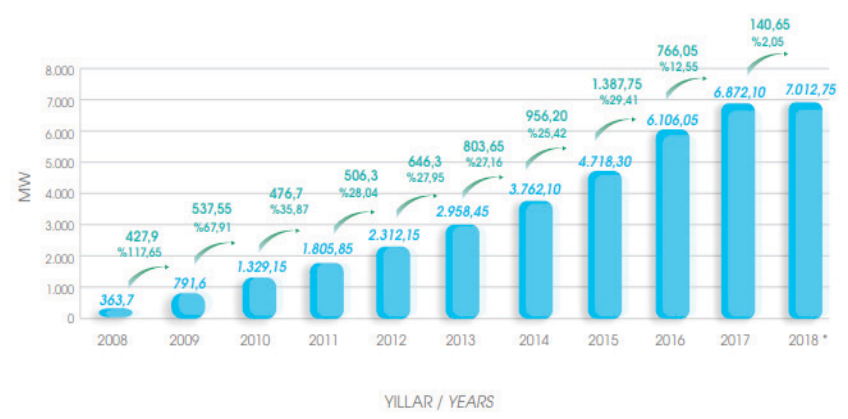

Şekil 3: Türkiye'de rüzgar enerjisi santralleri kurulu gücünün y1llara göre değişimi [10].

Literatürde rüzgar enerjisine yönelik çalışmalar; rüzgar türbinlerinin üretim ve kullanımlarına yönelik yaşam döngüsü analizlerine (YDA), teknik olarak rüzgar türbini kurulacak alanın seçiminde dikkat edilmesi gereken etmenlere ve rüzgar türbinlerinin çevresel etkilerine ve rüzgar enerjisinin 
kullanırlığını arttırmaya yönelik politika ve teşvik koşullarını araştııılmasına odaklanmıştır. Rüzgar türbinlerinin yaşam dönüsü üzerine yapılan çalışmalar, rüzgar türbinlerini çeşitli enerji üretim yöntemleri ile karşılaştırmaktadır [11]. Siddiqui ve Dinçer rüzgar türbinleri ile elektrik üretimini hidroelektrik ve nükleer elektrik üretimi ile karşılaştırmış. Rüzgardan elektrik üretiminin ötrifikasyon, asidifikasyon, fotokimyasal ozon oluşturma etki katagorilerinde diğer alternatiflere göre daha yüksek etki yaptığı ve bu ekilerin büyük oranda türbinlerin inşaası (kurulumu) aşamasında meydana geldiğini bulmuşlardır. Rüzgar türbinlerinin sera gazı salınımları ise oldukça düşük (12 g CO2 eş./kWh) bulunmuştur [11]. Diğer çalışmalar karasal [12] ve denizsel [13] rüzgar türbinlerinin yaşam döngüsünü araştırmıştır. Temel olarak, denizsel rüzgar türbinlerinin daha yüksek yaşam döngüsü etkisine sahip olması, kurulum aşamasında daha çok sabitleyici, yapıya ihtiyaç göstermesi sebebiyledir $[12,13]$. Ayrıca, kullanım ömrü biten rüzgar türbinlerinin bertarafı ve dönüştürülmesi de çevresel etkileri açısından önemlidir [11-14]. Bu bakımdan, rüzgar türbinlerinin ömür sonu işlemleri ve yenilenmeleri YDA ile incelenmiş ve türbinlerin ve elektrik aksamlarının yenilenmesinin çevresel etki kaynakları olduğu bulunmuştur. Ancak, bu etkiler yeniden kuruluma göre düşük olduğundan ömrünün sonuna yaklaşan rüzgar tarlalarının yenilenmesi çevresel açıdan yararlı bulunmuştur [14]. Rüzgar enerjisinin kullanımının ve rüzgar türbinlerinin kurulumunun artması ile birlikte oluşabilecek çevresel sorunlar ve bunların ortadan kaldırılması yada azaltılması için alınabilecek önlemler de çalışılmıştır $[2,15]$. Rüzgar türbinlerinin teknolojik ve tasarımsal olarak ilerletilmesi ve Türkiye'de kullanılan rüzgar gücü potansiyelinin arttırımlması için gereken destek makanizmaları da ayrıntılı olarak incelenmiştir [3,7].

Türkiye, Birleşmiş Milletler İklim Değişikliği Çerçeve Sözleşmesi ve Paris İklim Anlaşması çerçevesinde 2030 yılına kadar sera gazı salınımını normal işleyişe göre \% 21 azaltma, yani 246 milyon ton $\mathrm{CO}_{2}$ eşleniği sera gazı azaltımı taahhütünde bulunmuştur. Bunu, 2030 yılına kadar kurulu güneş gücünü $10 \mathrm{GW}$, rüzgar gücünü $16 \mathrm{GW}$ ’ta çıkararak ve hidroelektrik kapasitesinin hepsini kullanarak başaracağını, ayrıca elektrik iletim kayıplarını \% 15'e düşüreceğini beyan etmiştir [16,17].

Bu bağlamda çalışmamız Türkiye'nin rüzgar enerjisi ile enerji ihtiyacını karşılamak ve sera gazı azaltımı taahhütlerini tutturmakta bu enerjiden nasıl yararlanabileceği noktasında katkı sağlamaktadır. Burada, ekonomik bir rüzgar enerjisi yatırımı için 50 m'de $7 \mathrm{~m} / \mathrm{s}$ rüzgar hızı, 0,35 ve üzeri kapasite faktörü gerekliliklerine dayanılarak ve Edirne için rüzgar türbini kurulabilir alanlar, kapasite faktörü, rüzgar hız dağılımı, trafo merkezleri ve enerji nakil hatları ve ilçe nüfusları göz önüne alındığında Keşan ilçesinin rüzgar türbinleri kurulumu için uygun bir alan olduğu sonucuna varılmıştır. Çalışmamızda temel olarak,

- Keşan ilçesine mesken elektrik ihtiyacı rüzgar gücü ile karşılanabilir mi?

- Diğer enerji kaynaklarının kullanımı sonucu açığa çıkan sera gazı salınımları, rüzgar enerjisi ile elektrik üretimi sonucunda ne kadar azaltılabilir?

sorularının yanıtları aranmıştır. Bu bağlamda, çalışmamız rüzgar enerjisinin sera gazı salınımını azaltma potansiyeli ve Türkiye hedeflerine katkısını da araştırmaktadır. Makalenin devamı olan bölüm 2'de kullanılan yöntem ve hesaplamalar için yapılan kabuller açıklanırken, bölüm 3’te çalışma bulguları sunulmaktadır. En son bölümde ise çalışmadan çıkarılan sonuçlar ve değerlendirmeler sunulmaktadir.

\section{II.MATERYAL VE YÖNTEM}

\subsection{Elektrik Kullanımı ve Kurulu Güç Projeksiyonları}

Şekil 4 Edirne iline ait 50 m'de ölçülen rüzgar hızı ve kapasite faktörü dağılımlarını göstermektedir. Ekonomik bir rüzgar enerjisi yatırımı için $50 \mathrm{~m}$ 'de $7 \mathrm{~m} / \mathrm{s}$ rüzgar hızı, 0,35 ve üzeri kapasite faktörü değerleri aranmaktadır [5]. Bu parametreler ve tablo 1'de [18] verilen rüzgar hızı değerleri ış1ğında, Edirne ilinin rüzgar türbinleri kurulumu için uygun bir alan olduğu sonucuna varılmıştır. Ayrıca, Keşan ilçesi 0,35-0,45 arasında bir kapasite faktörüne sahip olduğundan, ilçe için ortalama 0,40 kapasite faktörü kabul edilerek [18] çalışmamızda mesken elektrik tüketiminin rüzgar enerjisi ile karşılanmasında incelenecek bölge olmasına karar verilmiştir.

Keşan ilçesinin incelenmesine karar verilmesiyle 2050 yılına kadar elektrik kullanım ve gerekli rüzgar gücü kurulumunun hesaplanabilmesi için TÜIK (Türkiye İstatistik Kurumu) verilerine göre ilçe için tahmini nüfus artışı $\% 0,93$ [19] ve ortalama yıllık kişi başı mesken elektrik tüketim artış1 \%6,00 olarak belirlenmiştir [20]. Buna göre, gerekli mesken elektrik üretimi Eşitlik 1 'e göre hesaplanmıştır. Burada n, 2018'den 2050’ye artan y1lları göstermektedir.

\section{Elektrik Üretimi $=$ Kişi Başı Tüketim $*(1+0,06)^{n} *$ Nüfus $*(1+0,0093)^{n}$}



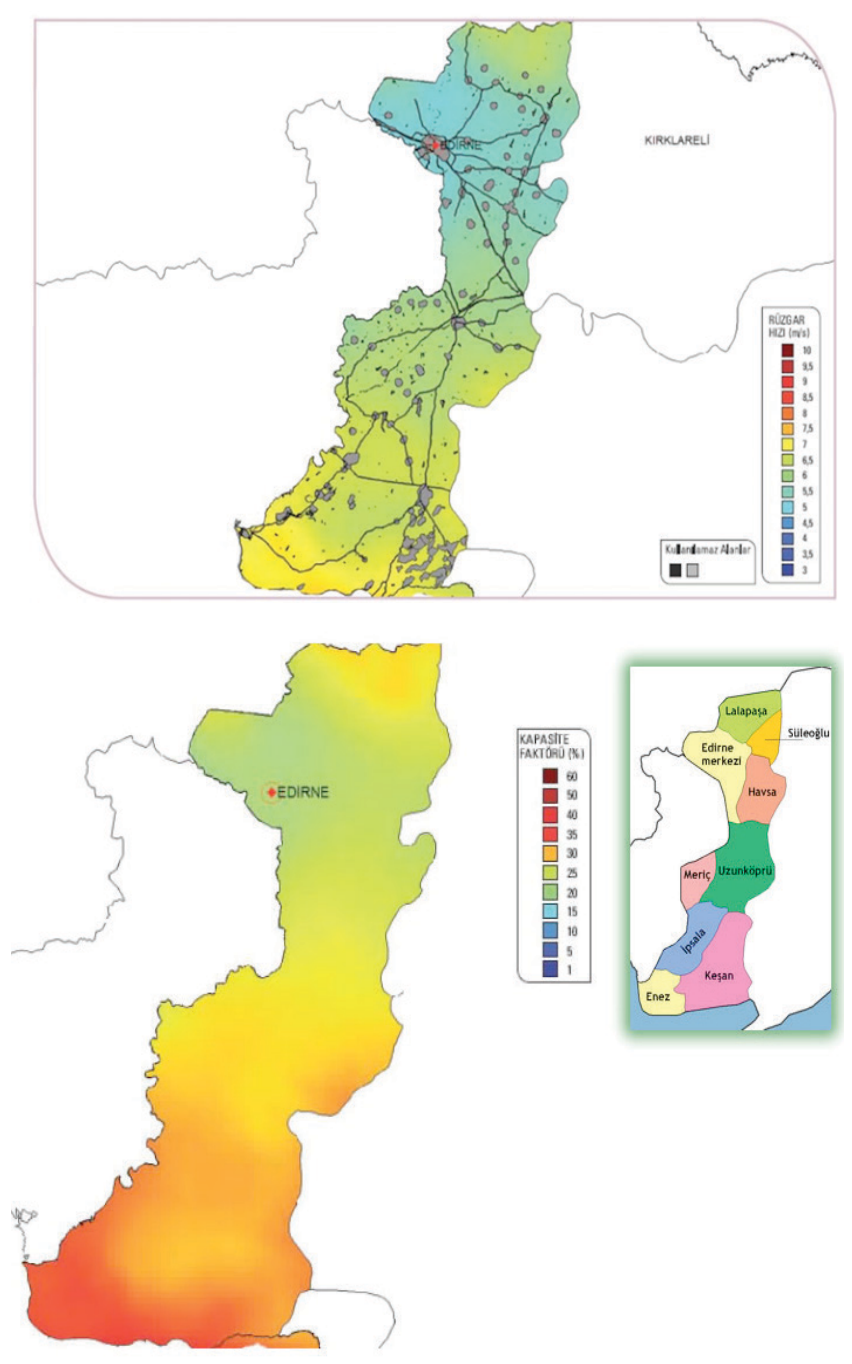

Şekil 4: Edirne için $50 \mathrm{~m}$ rüzgar hızı ve kapasite faktörü dağılımları [18].

Tablo 1: Edirne İline Kurulabilecek RES Güç Kapasitesi [18]

\begin{tabular}{|c|c|c|c|}
$\begin{array}{c}50 \text { m'de Rüzgar } \\
\text { Gücü }\left(\mathrm{W} / \mathrm{m}^{2}\right)\end{array}$ & $\begin{array}{c}50 \mathrm{~m} \text { 'de Rüzgar } \\
\text { Hızı(m/s) }\end{array}$ & $\begin{array}{c}\text { Toplam } \\
\text { Alan }\left(\mathrm{km}^{2}\right)\end{array}$ & $\begin{array}{c}\text { Toplam Kurulu } \\
\text { Güç }(\mathrm{MW})\end{array}$ \\
\hline $300-400$ & $6.8-7.5$ & 578,24 & $2.891,20$ \\
\hline $400-500$ & $7.5-8.1$ & 115,78 & 578,88 \\
\hline $500-600$ & $8.1-8.6$ & 0 & 0 \\
$600-800$ & $8.6-9.5$ & 0 & 0 \\
$>800$ & $>9.5$ & 0 & 0 \\
& & 694,02 & $3.470,08$ \\
\hline
\end{tabular}

Enerji ihtiyacının karşılanması için gerekli rüzgar gücü kapasitesi Eşitlik 2'ye göre hesaplanmıştır. Burada, kapasite faktörü rüzgardaki kinetik enerjinin ne oranda elektrik enerjisine dönüştürüldüğünü göstermektedir ve Keşan için 0,4 değeri alınmıştır [18].
Kurulacak Rüzgar Gücü $=$ Elektrik Üretimi $/(365 * 24 *$ Kapasite Faktörü $)(2)$

\subsection{Sera Gazı Salınımları}

Tablo 2 çeşitli enerji kaynaklarından elektrik üretildiğinde salınan $\mathrm{CO}_{2}$ aralıklarını ve bu üretim teknolojilerine ait ortalama salınım değerlerini göstermektedir. Buradaki ortalama salınım değerleri kullanırak ve şekil 5 de sunulan her kaynağın Türkiye elektrik kullanımına katkısı (\% olarak) hesaba katılarak Eşitlik 3'e göre Türkiye elektrik sektörünün sera gazı salınımları hesaplanmıştır. Eşitlik 3 'te n elektrik üretiminde kullanılan farklı enerji kaynaklarını temsil etmektedir. Burada, mevcut kullanım oranları ve salınım değerleri ile Türkiye'de elektrik enerjisi üretimi sonucu kWh başına $489 \mathrm{~g} \mathrm{CO}_{2}$ salınımı yapıldığı bulunmuştur. Rüzgar için ise $10 \mathrm{~g} / \mathrm{kWh}$ değeri kullanılarak iki durum arasındaki fark hesaplanmış ve rüzgar ile elektrik üretiminde ne kadar $\mathrm{CO}_{2}$ salınımının engellenebileceği hesaplanmıştır.

Sera Gazı Salımm $=\left(\sum_{k=1}^{n}\right.$ Ortalama Sera Gazı Salınım $*$ Kullanım Yüzdesi $) / 100$

Tablo 2: Enerji Kaynaklarına Göre Karbon Emisyon Değerleri

$$
\text { [21-23] }
$$

\begin{tabular}{|l|c|c|c|}
\hline Kaynak & $\begin{array}{l}\text { Min.-Max. Sera } \\
\text { Gazı Emisyonu } \\
\text { (ton-CO2/GWh) }\end{array}$ & $\begin{array}{l}\text { Ortalama Sera } \\
\text { Gazı Emisyonu } \\
\text { (ton-CO2/ } \\
\text { GWh) }\end{array}$ & $\begin{array}{l}\text { Bir Konuta } \\
\text { Düşen Emis- } \\
\text { yon (kg- } \\
\text { CO2-yıl) }\end{array}$ \\
\hline Linyit & $790-1.372$ & 1.054 & 3.689 \\
\hline İthal Kömür & $756-1.310$ & 888 & 3.108 \\
\hline Taş kömürü & $756-1.310$ & 888 & 3.108 \\
\hline Fuel-oil & $547-935$ & 733 & 2.566 \\
\hline Doğalgaz & $362-891$ & 499 & 1.747 \\
\hline Nükleer & $2-130$ & 66 & 231 \\
\hline Jeotermal & & 38 & 133 \\
\hline Biyokütle & $10-101$ & 26 & 91 \\
\hline Hidroelektrik & $2-237$ & 26 & 91 \\
\hline Güneş & $13-731$ & 23 & 81 \\
\hline Rüzgar & $6-124$ & 10 & 35 \\
\hline
\end{tabular}

2017 Yılı Elektrik Üretiminin Kaynaklara Dağılımı (Birim Değer MWh)

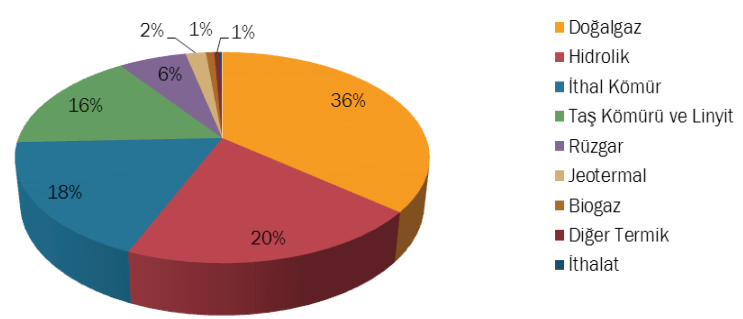

Şekil 5: 2017 Y1lı Elektrik Üretiminin Kaynaklara Dağılımı (Birim Değer MWh) [24]. 


\section{III.BULGULAR VE TARTIŞMA}

\subsection{Elektrik Kullanımı ve Kurulu Güc}

Şekil 6, 2018-2050 yılları arasında Keşan ilçesi için belirlenen kişibaşı elektrik kullanım artışı göz önüne alınarak hesaplanan mesken elektrik kullanımındaki değişimi gösterilmektedir. Buna göre, Keşan ilçesinde 2018 yılında kişi başı mesken elektrik tüketimi 806 kWh iken 2050 yılında bu tüketimin $5200 \mathrm{kWh}$ değerlerine yükseleceği hesaplanmıştır. $\mathrm{Bu}$ artışın, artan teknoloji ile birlikte artan kişisel elektronik eşyaların ve iklimlendirme cihazlarının kullanımına bağlı olduğu düşünülmektedir.

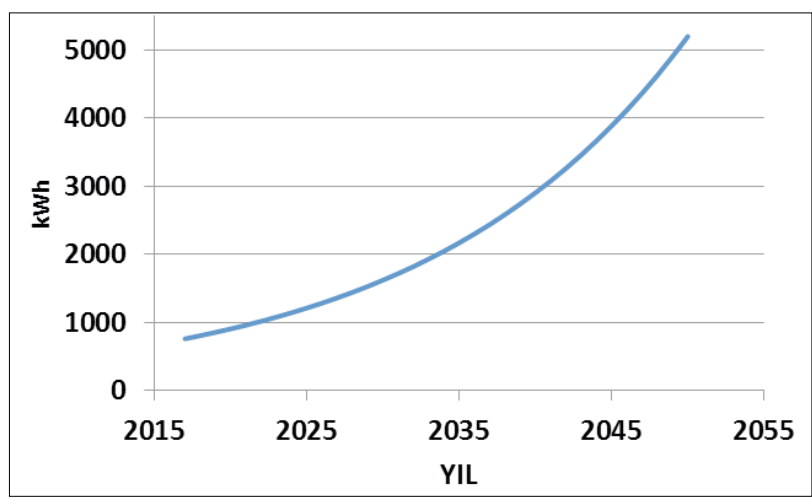

Şekil 6: Keşan ilçesi'nde 2050 yılına kadar kişi başına mesken elektrik kullanımının değişimi

Şekil 7'de 2018-2050 yılları arasında Keşan ilçesi için belirlenen nüfus artış hızı ve kişi başına elektrik kullanım artışı göz önüne alınarak hesaplanan toplam mesken elektrik kullanımındaki değişimi göstermektedir. 2018 toplam mesken elektrik tüketimi yaklaşık 62000 MWh iken 2050'de bu tüketimin 577000 MWh civarında olacağı hesaplanmıştır. Kişibaşı elektrik kullanımına benzer şekilde bu artışa esas olarak artan yaşam standardına dayanan enerji kullanım artışının sebep olacağı düşünülmektedir.

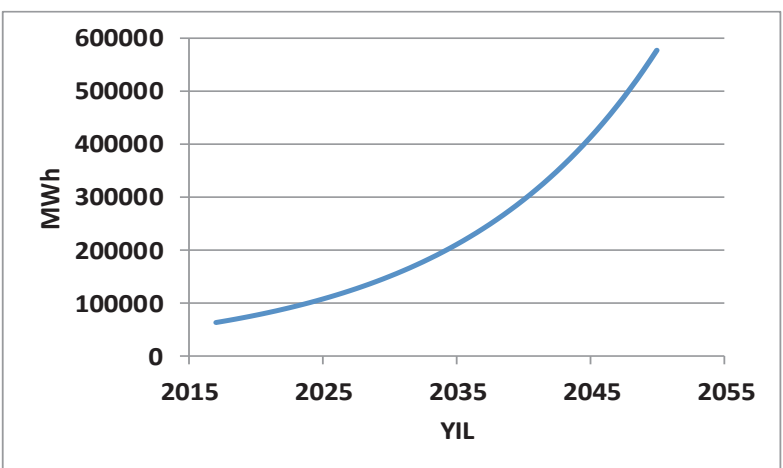

Şekil 7: Keşan ilçesi'nde 2050 yılına kadar toplam mesken elektrik kullanımının değişimi
Şekil 8, Keşan'da 2050 yılına kadar mesken elektrik enerjisi ihtiyacını karşılayabilmek için gerekli rüzgar gücü kurulumunun değişimini göstermektedir. Buna göre, 2018 enerji ihtiyac1 3'er MW'lık yedi adet rüzgar gülü ile karşılanabilirken 2050 elektrik ihtiyacı için aynı kapasitede 55 adet rüzgar gülü kurulumu gerekmektedir. Keşan bölgesinde rüzgar türbini kurulabilecek alanlar ve mevcut kapasite (Tablo 1'den 3470 MW) incelendiğinde, rüzgar enerjisi ile 2050 y1lına kadar bu ihtiyacın karşılanabileceği bulunmuştur.

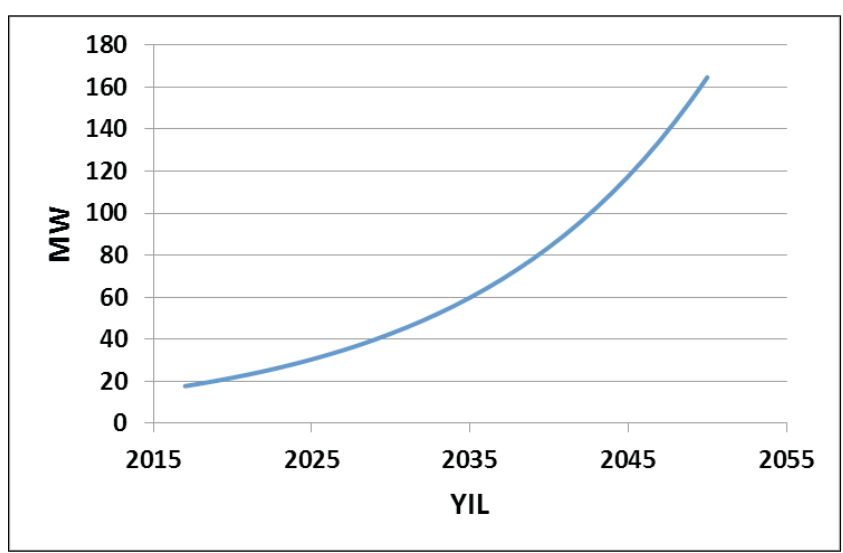

Şekil 8: Keşan ilçesi’nde 2050 yılına kadar gerekli kurulu rüzgar gücünün değişimi

\subsection{Rüzgar Gücüne Bağlı Sera Gazı Salınımı Azalması}

Şekil 9 logaritmik olup Türkiye'de mevcut kaynaklarla elektrik üretimi sonucu oluşan $\mathrm{CO}_{2}$ salınımı ile rüzgar enerjisinden faydalanılarak elektrik üretildiğinde oluşan $\mathrm{CO}_{2}$ salınım değerlerini Keşan özelinde karşılaştırmaktadır. Buna göre, rüzgar ile elektrik üretimi Keşan'da enerji üretimine bağlı $\mathrm{CO}_{2}$ salınımlarında \%97,96'lık bir azalma sağlamaktadır. Ayrıca, 2018'de engellenebilecek $\mathrm{CO}_{2}$ salınımı 30 bin ton iken hesaplamalarımıza göre bu sayı 2050'de 275 bin tona çıkacaktır.

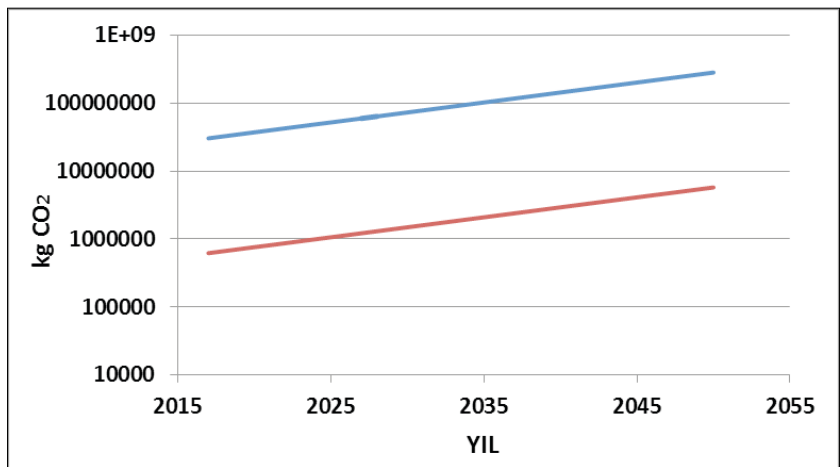

Şekil 9: Keşan ilçesi'nde mevcut kaynaklar ve rüzgar ile elektrik üretimi ile $\mathrm{CO}_{2}$ salınım değişimleri. Mavi: Mevcut kaynaklar; Kırmız1: Rüzgar 


\section{IV.SONUC VE DEĞERLENDİRME}

Çalışmamızda öncelikli olarak, ekonomik rüzgar türbini yatırımı için gerekli olan rüzgar hızı ve kapasite faktörü parametreleri ile trafo merkezleri ve enerji nakil hatları ve ilçe nüfusları gözönüne alınarak Edirne ili Keşan ilçesinin rüzgar türbini kurulumu için uygun bir bölge olduğu sonucuna varılmıştır. Daha sonra, artan hayat standardı ile birlikte, ilçede yıllık \%6'lık elektrik kullanım artışı ile 20182050 yılları arasında kişi başı mesken elektrik tüketiminin 806 kWh'ten $5200 \mathrm{kWh}$ değerlerine yükseleceği bulunmuştur. Türkiye'nin sera gazı salınımı azaltım taahhütlerinde de belirttiği gibi, Türkiye'de enerji kullanımı yılda \%6-7 oranında artış göstermektedir. Yine Keşan için ortalama \%0,93 nüfus artış hızı da göz önüne alındığında, ilçedeki toplam mesken elektrik tüketiminin 2018-2050 yılları arasında yaklaşık 62000 MWh'tan 577000 MWh'e çıkacağı bulunmuştur. İlçede mevcut durumda 3'er MW'lık yedi adet rüzgar türbini ile mesken elektrik enerjisi ihtiyacı ile karşılanabilirken 2050 yılında bu ihtiyacın karşılanabilmesi için 3'er MW'llk 55 adet rüzgar türbininin kurulumu gerekmektedir. Keşan bölgesinde rüzgar gülü kurulabilecek alanlar ve mevcut kapasite incelendiğinde, rüzgar enerjisi ile 2050 yılına kadar bu ihtiyacın karşılanabileceği görülmektedir.

Türkiye'de mevcut kaynaklarla elektrik üretimi yapılırken ağırlıklı olarak fosil yakıtlardan (özellikle ithal doğalgaz ve kömür) yararlanılmakta ve $1 \mathrm{kWh}$ elektrik enerjisi üretilirlen $489 \mathrm{~g} \mathrm{CO}_{2}$ eşleniği sera gazı salınımı yapılmaktadır. Mevcut kaynaklarla elektrik üretimi sonucu oluşan $\mathrm{CO}_{2}$ salınımı ile rüzgar enerjisinden faydalanılarak elektrik üretildiğinde oluşan $\mathrm{CO}_{2}$ salınım değerlerini Keşan özelinde karşılaştırıldığında enerji üretimine bağlı $\mathrm{CO}_{2}$ salınımlarında \%97,96'lık bir azalma görülmüştür. Ayrıca, 2018'de engellenebilecek $\mathrm{CO}_{2}$ salınım 30 bin ton iken hesaplamalarımıza göre bu sayı 2050'de 275 bin tona kadar yükselmektedir. Bu farklılık seviyeleri tam kapasite ile kullanıldığında, rüzgar enerjisinin Türkiye'nin sera gazı salınımlarını azaltma hedeflerine önemli katkılar sağlayabileceğini göstermektedir.

\section{KAYNAKLAR}

[1] Kumar Y., Ringenberg J., Deparu S.S., Devabhaktuni V.J., Lee J.W., Nikolaidis E., Andersen., Afjeh A. (2016). Wind energy: Trends and enabling technologies. Renewable and Sustainable Energy Reviews 53, 209-224.

[2] Dai K., Bergot A., Liang C., Xiang W.N., Huang Z. (2015). Environmental issues associated with wind energy: A review. Renewable Energy 75, 911-921.

[3] Kaplan Y. A. (2015). Overview of wind energy in the World and assessment of current wind policies in Turkey. Renewable and Sustainable Energy Reviews 43, 562-568.
[4] Ilkilic C. (2012). Wind energy and assessment of wind energy potential in Turkey.. Renewable and Sustainable Energy Reviews 16, 1165-1173.

[5] T.C. Enerji ve Tabii Kaynaklar Bakanlığı. http://www.enerji. gov.tr/tr-TR/Sayfalar/Ruzgar. Şubat 2018 tarihinde ulaşıldı.

[6] Burton T., Jenkins N., Sharpe D., Bossanyi E. (2011) Wind Energy Handbook. West Sussex, United Kingdom. WILEY, Second Edition.

[7] Manwell J.F., McGowan J.G., Rogers A.L. (2009). Wind Energy Explained: Theory, Design and Application. Sussex, United Kingdom. WILEY.

[8] Global Wind Atlas. http:/www.vindenergi.dtu.dk/english/ news/2017/11/mapping-the-worlds-wind-energy-potential?i-

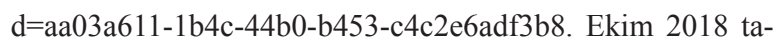
rihinde ulaşıldı.

[9] Türkiye Rüzgar Enerjisi Atlas1. http://www.yegm.gov.tr/ YEKrepa/REPA-duyuru_01.html. Şubat 2018 tarihinde ulaş1ld.

[10] Türkiye Rüzgar Enerjisi Birliği. Türkiye Rüzgar Enerjisi İstatistik Raporu Temmuz 2018. https:/www.tureb.com.tr/files/tureb_sayfa/duyurular/2018/08/istatistik_raporu_temmuz_2018.pdf. Ağustos 2018 tarihinde ulaşıldı.

[11] Siddiqui O., Dincer I. (2017). Comparative assessment of the environmental impacts of nuclear, wind and hydro-electric power plants in Ontario: A life cycle assessment. Journal of Cleaner Production 164, 848-860.

[12] Xua L., Panga M., Zhanga L., Poganietzb W.R., Marathe S.D. (2018) Life cycle assessment of onshore wind power systems in China. Resources, Conservation \& Recycling 132, 361368.

[13] Huang Y.F., Gan X.J., Chiueh P.T. (2017). Life cycle assessment and net energy analysis of offshore wind power systems. Renewable Energy 102, 98-106.

[14] Martineza E., Latore-Bielb J.I., Jimenezc E., Sanza F., Blancoa J. (2018). Life cycle assessment of a wind farm repowering process. Renewable and Sustainable Energy Reviews 93, 260-271.

[15] Abbasi T., Premalatha M., Abbasi T.A., Abbasi S.A. (2014). Wind energy: Increasing deployment, rising environmental concerns. Renewable and Sustainable Energy Reviews 31, 270-288.

[16] Küresel Karbon Atlas1. http:/www.globalcarbonatlas.org/en/ CO2-emissions. Ekim 2018 tarihinde ulaşılmıştır.

[17] Türkiye Cumhuriyeti Ulusal Katkı Taahhütü https://www4.unfccc.int/sites/submissions/INDC/Published\%20Documents/Turkey/1/The_INDC_of_TURKEY_v.15.19.30.pdf. Ekim 2018 tarihinde ulaşıld1.

[18] Edirne İli Rüzgar Potansiyel Atlası. T.C. Enerji ve Tabii Kaynaklar Bakanlığı, Yenilenebilir Enerji Genel Müdürlüğü. http://www.eie.gov.tr/YEKrepa/EDIRNE-REPA.pdf. Aralık 2017 tarihinde ulaşıldı. 
[19] Türkiye İstatistik Kurumu Temel İstatistikleri, Nüfüs Projeksiyonları

http://www.tuik.gov.tr/UstMenu.do?metod=temelist. Nisan 2018 tarihinde ulaşıldı.

[20] Türkiye İstatistik Kurumu Temel İstatistikleri, Çevre ve Enerji

http://www.tuik.gov.tr/UstMenu.do?metod=temelist. Nisan 2018 tarihinde ulaşıldi.

[21] Melikoglu M. (2013). Vision 2023: Feasibility analysis of Turkey's renewable energy projection. Renewable Energy 50, 570-575.
[22] Comparison of lifecycle greenhouse gas emissions of various electricity generation sources, World nuclear association report, World nuclear association (WNA), London,UK. http://www.worldnuclear.org/uploadedFiles/org/WNA/Publicat ions/Working_Group_Reports/comparison_o f_lifecycle. pdf

[23] Savacool B.K. (2008). Valuing the greenhouse gas emissions from nuclear power: A critical survey. Energy Policy 36, 2950 $-2963$.

[24] T.C. Enerji ve Tabii Kaynaklar Bakanlığı, Kaynaklarına Göre Elektrik Üretimi

http://www.enerji.gov.tr/tr-TR/Sayfalar/Elektrik. Nisan 2018 tarihinde ulaşıldı. 